\title{
Perception, Empiricism, and Pragmatist Realism
}

\author{
Serge Grigoriev
}

\begin{abstract}
This article compares Peirce's pragmatist approach to the problem of perceptual experience as a fallible foundation of knowledge with the approach taken by a sophisticated empiricist position. While empiricism can accommodate the idea of perception as fallible, theoretically laden, and containing conjectural elements, the cardinal difference between pragmatism and empiricism consists in the pragmatist insistence on the intrinsic intelligibility of experience, which also serves as the ultimate source of all forms of intelligibility. Empiricism, however, retains a penchant for fitting experiences into abstract conceptual schemes.
\end{abstract}

1.

Despite the impressive scientific accomplishments of the previous century, we are today less than ever inclined to take knowledge for granted. Gone is the faith in unproblematic epistemological givens, in a secure foundation of infallible protocol sentences unequivocally derived from experiential data; equally gone is the initial confidence of simplistic falsificationism. This is a good sign: it indicates that an advanced understanding of our epistemic practices is not likely to give comfort to philosophical utopias and, conversely, to the extreme forms of skepticism that tend to mushroom when these utopias fail. However, it does set before us a task of figuring out anew a viable theory of perception's function in knowledge. As I take it, most of us still believe that (at least some) perceptual experiences have a special role to play in our efforts to understand the world and ourselves within it.

For pragmatists working within the realist vein, this is a high-stakes issue, both strategically and substantively. On the side of the substantive challenge, pragmatists believe that the meaning of our statements is supposed to be ultimately expressed in terms of their publicly verifiable consequences, and that in order to advance, our beliefs must always remain evidence-responsive (Misak 1991, 60; cf. CP 7.78). ${ }^{1}$ Hence, pragmatism cannot succeed without giving a satisfactory account of the nature of evidence to which we hold ourselves answerable. On the side of strategy, the problem of the relationship between perception and knowledge supplies the natural ground on which to stake out the 
claim for pragmatism's conceptual independence and significance vis-à-vis the various derivatives of traditional empiricism which still, for the most part, dominate our philosophical markets. Based solely on the roughly verificationist commitment cited above, it may be tempting to say that pragmatism is merely a set of suggestions for improvement on the traditional empiricist themes coming from outside the analytic mainstream. This is an impression that pragmatists may want to oppose.

The strategic and the substantive issues are intertwined insofar as one of the routes to clarity on the substantive issue lies through elucidating the relationship between empiricism (and positivism) and pragmatism. In order to count as a response and a corrective to empiricism (rather than yet another refinement thereof) pragmatism has to show that, in the crucial area of empirical commitment, it can supply something that empiricism proper could not. Substantial gains of the required sort have been made by pragmatists in the discussions surrounding the fact/value dichotomy - which positivists affirmed in the name of neutrality of science, and pragmatists denied in the name of the continuity between different kinds of judgments (Kuklick 2006, 552). That contest, it seems, has yielded a sense of pragmatism's advantage, with influential analytic figures like Putnam now arguing that facts presuppose values epistemic values, to be sure - but values, nonetheless, which have no external justification (Putnam 2002, 30-33). Yet when it comes to the problem of perceptual evidence, what we lack is precisely the sense of a well-defined contest; what we have are some vague premonitions of a putative advantage had the contest been held. Pragmatists today cannot score their points by attacking strong foundationalism, or strong coherentism which has no traction on the external world. Both can be safely regarded as odd fashions of seasons past. There must be a stronger contribution in the offing than one that simply discounts the already floundering dogmas.

In search of potentially promising leads, this essay attempts a comparison of two historical positions: one empiricist and one pragmatist. Peirce, of course, makes for a natural choice on the pragmatist side, for not only was he a subtle systematic philosopher, but he also a practicing scientist. Peirce proudly avowed during one of the formative periods of his intellectual career, in his Cambridge discussions with Wright, James, and others, that the spirit of empirical science "a decidedly British" (CP 5.12 1907) spirit - dominated his thought. Wright (my choice of an empiricist) is a less familiar name, albeit undeservedly so. Once Peirce's intellectual sparring partner, ${ }^{2}$ Wright was a self-proclaimed positivist and an ardent admirer of Darwin and Mill. Choosing Wright, as opposed to a later empiricist figure, is advantageous in several ways. First, between Wright and Peirce there is a shared background of intellectual concerns, from scientific method, to evolution, and to post-Kantian philosophy; thus a difference between their positions is more likely to be traced to a difference in intellectual orientations than to differences in historical background. Second, by dint of being a nineteenth century positivist and empiricist, Wright was free from the 
distorting influence of the palpable conceptual excesses of logical positivism. For example, under Mill's influence, he had already discarded the atomistic view of the given (which the twentieth-century empiricists had to struggle against), and maintained "ahead of his time" that perceptual judgments contain a conceptual element, conditioned by a wider network of pre-existing beliefs. Insofar as his empiricism was concerned more with what philosophy can learn from scientific reasoning than with putting science on some kind of unassailable philosophical foundation, Wright was intellectually closer to our present philosophical preoccupations than many of the later-day empiricists. ${ }^{3}$

On several occasions, Edward Madden (1963, 81; 2000, xxiii) suggested that a comparison between Wright's and Peirce's views on the "given" highlights the decisive discontinuity between pragmatism and its positivist and utilitarian predecessors. ${ }^{4}$ Madden is right about the significance of the comparison but, in my opinion, he is missing the precise nature of the difference at stake. On Madden's view, what Wright affirms (Madden 2000, xxiii) and what Peirce unequivocally denies (Madden 1972, 49) is the "self-containedness of the given," meaning the empiricist position that some concepts are just summaries of particulars, which do not contain any hypothetical element and can, therefore, be taken as primitive (Madden 1953, 68). I first argue that Wright's position on the "given" must be much more nuanced than Madden's comment suggests. ${ }^{5}$ I next offer an explanation of what is meant by the "hypothetical element" in Peirce's theory of perception. In the closing section, I assess the significance of the differences between Wright's and Peirce's positions (with respect to the relationship between perception and knowledge) for our current understanding of the relationship between pragmatism and empiricism.

\section{2.}

Madden's argument strongly depends on interpreting Peirce's position on perception in a way that conflates two separate (but not unrelated) moments: the problem of recognition and the problem of commitments that one incurs by describing experiences as experiences of a certain sort. On the view that Madden attributes to Peirce, recognizing an object as an object of a certain kind, say a "hard" object, requires forming hypotheses about its future behavior, thus going far beyond what is given immediately in experience. There is no textual evidence, as Madden justly contends (Madden 1963, 81), that Wright would have been drawn to such an unusual view. Wright, according to Madden, would not be inclined to regard a simple observational statement about an object as a hypothesis about its future behavior; instead he would see it as an act of classification based on some of the object's apparent properties and our past experience with similar objects (Madden 1958, x; 1972, 49). If what is meant by a "hypothetical element in perception" is a set of conjectures about the way that the object perceived may respond to future manipulation, and if "self- 
containedness of the given" refers to the view that we recognize objects and events without simultaneously forming predictions about their future behavior, then Wright would land clearly on the side of the "given" as opposed to the "hypothetical."

However, this interpretation leaves the pragmatist with an unnecessarily counter-intuitive view of perception. When one says "this is hard" upon hitting the floor or "lo, a rabbit" when surprised by the rabbit's appearance from the tall grass, it is difficult to convince ourselves that one is trying to engage in predictions of any kind. A simple recognitional habit would do just fine. Now, outside artificial settings, recognitional habits often translate into behavioral responses coordinated with the expected developments that normally follow upon having certain perceptions. But to deny that is not to reject pragmatism; it is to reject our basic evolutionary capacity for survival. Thus, for all his natural sanguinity, Wright would probably agree that in certain circumstances an observation “lo, a tiger” refers as much to one's impending doom as it does to one's past experiences. To avoid a conceptual muddle, we can introduce a distinction between two stages of perceptual experience: recognition of our experience as experience of a certain sort, and an understanding of what such experiences normally entail. One is concerned with the (provisionally assigned) identity of the experience at hand, and another, with its meaning. Coincidentally, according to Madden's account, a corresponding distinction between "believing a proposition to be true" and "knowing fully what that proposition means" (Madden 1963, 97) was fully operational in Wright's own thought.

With this in mind, we could try to capture the intended contrast between Wright's empiricism and Peirce's pragmatism by saying that an empiricist holds that the first stage of perceptual judgment is conceptually independent from the second, while a pragmatist insists on an indispensable relationship between the two. Thus, on the pragmatist view, to count as having a perceptual belief requires having some idea of what this belief entails; while on an empiricist view, it merely requires having some prior beliefs to which a new one can be assimilated. This, however, may prove to be a false opposition, for it entirely ignores the problem of the cognitive context of our utterances. Pragmatism's insistence on understanding the implications of our responses/beliefs, rather than simply responding/believing, only makes sense within what Sellars called "the space of reasons”: i.e. the conceptual space where doubts can be raised about the veracity of our experience, where beyond reporting what we experience we may be asked to endorse or not endorse our report as a starting point for knowledge. A "considered" report that we make in such a context is very different from a spontaneous (and often provisional) recognition of experience as being an experience of a certain familiar sort. It is far from clear that, given such a cognitive context, an empiricist like Wright would be content to demand much less in terms of explicit awareness of the implications of one's (experiencebased) declarations than a pragmatist does. The remainder of my argument in this section is intended to suggest that he probably would not. 
To begin with, it seems misleading to characterize Wright's position in terms of a belief in the "self-containedness of the given." The expression is strongly suggestive of a view that perceptual reports are free from any admixture of mind-dependent elements. This is not Wright's view, and it is not a view that Madden could have possibly intended to attribute to him. Guiffrida, who has followed this line of interpretation, eventually found himself ascribing to Wright an "unusual position of accepting the self-containedness of the sensuous given while rejecting the incorrigibility thesis" (Guiffrida 1988, 59). If the "selfcontainedness" is taken in its most obvious sense and by "incorrigibility thesis" we mean the idea that perceptual judgments are not subject to correction, then "unusual" begins to sound a lot like "incoherent." There is, of course, no reason to credit a philosopher with an incoherent position, unless no better alternative can be found.

A simple way to avoid this conundrum is to distinguish between Wright's view and the more traditional view of the "given" inadvertently suggested by Madden's somewhat unfortunate turn of the phrase. Wright is certainly an empiricist, but he is also a naturalist, and within the evolutionary framework of his thought the distinction between the inside and the outside loses its metaphysical import. Objectivity, on his view, does not consist in mere externality: externality does not secure objectivity, nor does internality undermine it. The distinction between the external and the internal, according to Wright, is purely functional, drawn and redrawn with a view to increasing our epistemic success (Wright 1958, 86; 2000, 219), understood in terms of distinguishing between reality and a dream reliably enough to ensure security and survival (Wright 1958, 89). Accordingly, he does not believe that a proper account of perception can posit a principled division between the external contributions and contributions of the mind (Wright 2000a, 271). This is a position starkly at odds with the classical empiricist view of the "given."

As Madden himself points out, Wright believed that all perception contains a conceptual a priori element, without which it could not be rendered intelligible (Madden 1963, 124). New experience, according to Wright, acquires its meaning for us by being compared and related to our previous experiences preserved in memory; so it is this mnemonic framework that spontaneously supplies the conceptual interpretation of a particular experience (Wright 1958, 67; 2000a 124). "Of the manifold of a presentation," says Wright, "only parts are retained in the mind and remain adherent to one another; and this selection is determined a priori, by the orders of impressions already experienced, or else by an order inherent in the very nature of the intellect" (Wright 1958, 67; 2000a, 125). Apart from this selective assimilation sensory impressions would lose all connection to consciousness and remain unintelligible (Wright 1958, 68; 2000a, 126). Therefore, the notion of bare sense data can only be understood as a theoretical posit of our epistemological theory (Wright 1958, 71), and not as something that is given to us in experience. Comparing his position to Kant, whose doctrine he considers "vague enough ... but not self-contradictory" 
(Wright 2000, 374), Wright only emphasizes the empirical origin of the a priori elements in either our own experience or that of our ancestors (Wright 2000, 347).

Despite all this, Wright's position retains an important affinity with the classical empiricist view insofar as he regards perception (mediated though it may be by the empirical a priori elements) as a matter of pure receptivity. Wright has a clear grasp of the idea (later popularized by N. R. Hanson) that perception is theory-laden; however, he is equally committed to the idea that the intellect's operation in perception is "merely passive" (2000a, 96). In this respect, he remains a faithful disciple of John Stuart Mill, who taught that despite the spontaneous operation of the inferential processes in observation, we must regard the resulting pronouncements as a species of observation, not of inference (1961, IV, I, 3) ${ }^{6}$ Heeding this, we may try to re-capture the intended contrast between empiricism and pragmatism by saying that, unlike a pragmatist, an empiricist of Wright's sort refuses to treat perception as an inferential process. This is probably close to what Madden must have meant by contrasting the "self-containedness" of the empiricist to the "hypothetical" element of the pragmatist.

Nevertheless, it may pay to press things a little bit further. Both Mill and Wright are unequivocally committed to the important epistemic role that observation statements play in public discourse. Yet, to make such statements we need to subsume the particular experiences we are having under general categories corresponding to the publicly recognized concepts. Since we cannot logically infer a general (determinable) concept from a particular (determinate) experience, it is tempting to say that our observational statements are put forth hypothetically as candidates for a publicly adequate description of what has transpired before us. Proceeding this way changes the logical form of observational statement from "lo, a rabbit!" to (where it matters epistemically) "is that really a rabbit?," thereby introducing a reflexive element into an otherwise automated perceptual judgment. To yield on this point is to yield in the direction of pragmatism (as described above); and, on first examination, Mill (at least) is hardly inclined to do so. According to him, true inference always proceeds from particulars to particulars (II, IV, 3), with general statements serving merely as a cognitive halting-place of no particular significance (II, III, 6). However, this endearingly brave nominalism comes with a price: for we are compelled to admit that every objective fact stated in public discourse must be "grounded on a corresponding subjective one" arrived at by an "inscrutable" process (I, IV, 1).

Fortunately, Mill does not simply leave the matters at that. Although the ascent to the general is not required for reasoning strictly speaking, without it, we remain confined to practical reasoning, incapable of reflexively explaining its own operation (II, III, 3). Thus, we see or observe things immediately, without considering the basis of our belief or reliability of the processes by which it was derived. "It is good to assure ourselves," - says Mill, - "that the process has been performed accurately; but the testing of the process is not the 
process itself" (II, III, 8). The assurance, he continues, is not required for reasoning but for reasoning correctly (ibid.). Yet, for reasoning correctly the ascent to the general is required unconditionally.

The distinction between practical and reflexive cognition is a very important one for Wright, and "practical" is hardly the privileged term of the pair. Wright believed in a strong separation between scientific and practical interests, ${ }^{7}$ primarily because he thought that in practical matters the natural inclinations and the force of habit provide a more reliable and readily available guide to action $(1958,60)$. Scientific thinking, on his view, along with the rest of our "higher" non-practical preoccupations is distinguished (1) by self-conscious reflexive employment of mental faculties and awareness of the logical structure of one's reasoning; (2) by fully involving the "generative powers of evolved, developed, socialized, and acculturated human agents" (1958, 22); and (3) by serving the "objective motive" of curiosity and desire to remedy the felt imperfections of knowledge $(1958,10) .{ }^{8}$ Moreover, the relationship between these two types of cognition is an evolutionary one. According to Wright, practical or enthymematic thinking is common to both human beings and animals; while the particularly human form of consciousness, which results from the evolutionary enhancement of attention and memory, is distinguished by the capacity to reconstruct one's chain of reasoning as a complete syllogism, including the general premise (Wright 1958, 73-75). "The animal," says Wright, "has in mind only an image of the sign, previously present in perception, followed now immediately by an image of what was suggested through the obliterated mental image. But the latter, in the higher degrees of intelligence, is distinctly recalled as a middle term" (Wright 1958, 79), enabling thereby a reflexive analysis of one's thought.

Would it be too much of a stretch to suggest that what applies to thought in general should apply to observation as well? Would Wright resist the idea, that although ordinarily perception is quite automated and un-reflexive, where it matters epistemically we should demand a more self-aware type of perception, the kind that assumes the form of an explicit hypothesis susceptible to testing and refutation? Maybe so. As Madden remarks, while being fully aware of the value of the hypothetical method (Wright 2000, 198), Wright only applied it to theories and not to observations (Madden 1958, x; 1972, 49). Yet, at the same time, Wright must have shared Mill's concern with the limitations of ordinary observation, as well as his interest in observations generated in a controlled experimental fashion (III, VII, 4; III, VIII, 1). More importantly, Wright did not draw as sharp a boundary between observation and theory as Madden's commentary would suggest. "Facts and theories," says Wright, "are not coordinate species. Theories, if true, are facts - a particular class of facts indeed, generally complex ones, but still facts. Facts, on the other hand, even in the narrowest signification of the word, if they be at all complex and if a logical connection subsists between their constituents, have all the positive attributes of theories" (Wright 1958, 4). We can convert a theory into a fact by adding what 
Wright calls a "simple verification": as when Pascal had the Torricellian tube "carried up the Puy de Dome, and thus showed that the mercurial column was sustained by the weight of the atmosphere," bringing thereby "the theory of atmospheric pressure nearly down to the level of a fact of observation" (Wright 1958, 4-5). Wright does not provide an analogous example of what it would mean to regard a fact as a kind of theory. Perhaps it would mean forming testable conjectures about the bearing of observational conditions on what is being observed or something of that sort. The important point is that in accepting the idea that observational facts, under epistemically demanding circumstances, can be treated as provisional conjectures or theories would not turn Wright into a pragmatist; it would only make him a more cautious empiricist who puts a premium on experimental verification.

\section{3.}

On the view advocated here, nothing prevents an empiricist from recognizing that perception is theory-laden and corrigible and that, in some circumstances, perceptual reports are better regarded as hypotheses to be tested than as unassailable starting points for empirical reasoning. Advancing to a pragmatist position requires something more; and one of those things, on the argument that follows, is a willingness to reconsider the role of what may be called the "grid metaphor" in our reasoning about reasoning and perception. What is meant here by the "grid metaphor" is the philosophers' inveterate propensity, at least since the time of the moderns, to picture and reconstruct our conceptual apparatus more geometrico: as networks, foundationalist pyramids, webs of belief, differential matrixes, etc. This structuralist penchant for graphical order has had and still does have its uses; it is a powerful heuristic which can generate legitimate insight, but only as long as we do not forget that what we have in this image is a schematism, a metaphor and not a literal description of mental processes. Thus, perceptual events impinge on our consciousness and not on conceptual networks or webs of belief (as the descriptions abounding in the empiricist literature of the last century tend to insinuate). Conceptual networks will have their place in a reasonable account of perception; and so will the stimulation of our sensory surfaces; yet, such an account cannot be complete without including a phenomenology of perception - one pragmatist theme which traditional empiricists continue to stubbornly ignore.

It is not my intention to offer such a theory here; instead my plan is to search Peirce's pragmatist account of perception for clues about the kinds of conceptual adjustments that the pursuit of such a theory is likely to wring from an empiricist mindset. We will begin, however, with an account of perception which is rather an extension of the empiricist one, albeit filled out with a pragmatist emphasis on the peculiar dynamic between expectation and revision. A model of this sort is defended, for example, by Sandra Rosenthal who explains that our first conscious perceptual cognition, "the perceptual judgment 
in its narrow sense" is "the primitive abductive hypothesis of a present repetition of past experiential content" which becomes such a repetition "only as the perceptual judgment does assimilate it to those contents in the abductive process of recognition" (Rosenthal 2004, 196). With the exception of the abductive element, which needs to be spelled out, this picture is not radically different from what a sufficiently sophisticated empiricist would have to offer. To see why this is so, we need to begin with Peirce's insistence that we cannot have any beliefs, including perceptual, that are not interpreted in terms of prior beliefs. The point has been sufficiently stressed starting with some of earlier commentators (e.g. Murphey 1961, 71, 77-78); the question now is what's to be made of it. We shall discuss one option in detail, an option which is, in my opinion, implicitly favored by the empiricist-leaning accounts like Murphey's or Rosenthal's; and then I will turn to another less familiar one.

We can interpret "prior beliefs" to be a conceptual framework woven by past experiences - a kind of organizing (propositional) scheme with which we confront every new experience. For the most part, new experiences will be effortlessly assimilated to or subsumed by the conceptual network, rendering them intelligible in terms of their relationship to previous experiences. Occasionally, however, a new experience will not be caught by the network in the right way prompting a disturbance, a doubt, and a simultaneous concern about the adequacy of our perception and the adequacy of our conceptual framework. This model accords well with Peirce's emphasis on the special role that a surprise, a disappointment, a violation of expectations plays in our cognitive life whenever a "hard fact" compels us to change the way we think (CP 1.324 1893; CP 2.173 1902; CP 5.51 1903). It also helps us relate Peirce’s view that "there is no intuition or cognition not determined by previous cognitions" (W 2.224) to contemporary empiricist concerns, whether it be Quine's thoroughgoing holism or Sellars' insistence that we cannot have concepts pertaining to observable properties of physical things until we acquire a much broader conceptual framework (Sellars 1997, 45). As Rosenthal points out, it is the violation of our expectations that first focuses our attention on the problem of appearance as distinct from veridical perception (2004, 197); it is doubt that prompts us to locate our perceptual experience within the logical space of epistemic concerns. The distinctive feature of Peirce's contribution, on this tally, consists in anticipating early on the view that there can be no logical connections between perceptions and the sentences that describe them and refusing to reconstruct this missing connection in the straightforwardly associationist or behaviorist manner favored by the later empiricists. "What you see," says Peirce, "is an image and has no resemblance to a proposition, and there is no logic in saying that your proposition is proved by the image (CP 6.95 1903). However, perception influences propositional thought and usually does so in a fairly determinate fashion; therefore, a significant connection of some sort must obtain. 
Peirce's own account of the relationship between perception and perceptual judgment is complicated by the apparent ambiguity in his use of some of the key terms, ${ }^{9}$ but the general picture that emerges seems reasonably clear. Perception begins with a sense of something impinging upon us from the outside, a sense of interruption, of entering into a relationship with something external. The sense of "duality" or "polarity" that results is ordinarily passed over on our way to a fuller impression, and the closest that we come to experiencing it in isolation is when we are taken completely by surprise - so much so that the sense of shock momentarily eclipses the perception of its cause, leaving us with a mere sense of relating to something, a sense of duality without comprehension (W 3.185; CP 5.53 1903). Perception terminates in a perceptual judgment which is uncontrolled - both in being spontaneous, insofar as we cannot help making one the moment we look at something (CP 5.55 1903; CP 7.627 1903), and in being unreasoned, insofar as it rests on no prior conscious premise (W 5.328). Thus, when asked, under standard conditions, what makes us think that the chair is yellow, we can only say that it looks yellow - thereby merely restating our original perceptual belief with less confidence. There are no real reasons to be given.

Between the initial sense of impingement and the spontaneously formed perceptual judgment lies the territory of the percept, or the image proper: a murky territory in Peirce's account as we have it. The ambiguity in the use of the term "percept," explicated admirably by Hausman (1990), may be explained by the fact that Peirce thinks of perception as a process, with its content rapidly evolving over a very short stretch of time; therefore, "percept" designates not an entity or a point but a motion which swings, uninterrupted, all the way from a peripheral and barely legible trace (as when one sees something moving to the left, out of the corner of one's eye) to a fairly articulate image (say, that of a young man entering the room) which the eventual judgment claims itself to represent and refer back to. If this is right, then we can say that at the moment of its emergence the percept (or image) is not (logically) analyzable, since it impinges on us "in its entirety" without any conscious awareness or contribution on our part (CP 7.6241903 and W 5.328). To have a percept one merely needs to see, i.e. to have an image registered by one's retina (CP 7.627 1903). Hence, at this stage, the percept (as an incipient image) is "absolutely dumb," "it does not address the reason" (CP 7.622 1903), and does not purport to represent anything (CP 7.630 1903). It is something of a visual glitch. It is perfectly singular, with no generality, containing only firstness and secondness - i.e. a mere quality of feeling of a certain intensity (CP 7.625 1903). It is a "that over there": perfectly general in the sense of being almost completely indeterminate, i.e. lacking in general (predicative) determination.

"You see something," says Peirce, but you do not see a proposition such as " $x$ is red" (CP 6.95 1903). Hence, there is a problem of getting from what we see to what we say about it. On Peirce's view, perceptual judgment (which is propositional in form) relates to its object "as that object is represented" - 
therefore, it relates to a percept (ibid.). We experience objects (directly); but our (initial) judgment is based on the way we experience them. Now, perceptual judgment is supposed to state the character of the experienced percept, but can no more resemble it than a sentence can resemble an image (CP 5.54 1903). The substantial lack of structural (not to say essential) isomorphism between image and sentence introduces a moment of incommensurability within the very structure of perceptual cognition, where "incommensurability" is not taken to mean that we cannot, in principle, calibrate a description to an image, but merely that there are no logical rules for correctly translating between the two. "I could not hope," Peirce writes, "to describe what I see, feel, and hear, just as I see, feel, and hear it. Not only could I not set it down on paper, but I could have no kind of thought adequate to it or any way like it” (CP 2.141 1902). Peirce explains that the perceptual judgment represents the percept "as an index, or true symptom" and its "forcefulness" falls short of that of the percept only insofar as it "does profess to represent the percept" (CP 7.628 1903). Thus, perceptual judgment is not based on a percept, in the way that a conclusion is based on a premise; instead, it is prompted or compelled by a percept unreasoningly and is thereby placed beyond the pale of rational criticism (CP 5.116 1903).

Yet the logical form of perceptual judgment is such that it presents itself as representing the percept and (in that sense) being based on it. However, we need to be careful because the percept or image that becomes associated with the perceptual judgment - say, the remembered visual image of a young man which prompted me to say "there is a man in the room" - could not be equivalent to the percept as the emerging image, i.e. to the percept as we have described it so far. For one thing, when viewed retrospectively from the position of an accomplished judgment, the percept presents itself as a fixed image, not a process; secondly, it is fully conscious and available to scrutiny; thirdly, it possesses a good deal of determinacy. It is a percept framed, i.e. what we normally think of as a "perceptual image."

The fact that such a framed percept ${ }^{10}$ becomes available to us simultaneously with the formation of the spontaneous perceptual judgment is all the more significant because it allows us to raise, post factum, the question about the adequacy of our initial judgment, thereby enabling us to think critically about perception. Thus, Peirce discusses passing a "judgment about a percept" as a result of deciding "to contemplate" it "once having a percept" (CP 7.626 1903), as well as attempting an "imperfect description of the percept" which is not forced on me but is "the product of reflection" (CP. 2.141 1902). In the emerging percept there is nothing to contemplate; and the initial perceptual judgment is uncontrolled and contains no reflection. Yet, when the percept is framed or rendered more determinate in the initial judgment it can be consciously contemplated, described, and, most importantly, doubted. We could perceive and even have perceptually occasioned thoughts, without ever being able to articulate the questions about veridicality and reliability of perception. It would probably never occur to us to ask those questions if it weren't for the fact 
that spontaneous perceptual judgments purport to represent something which they simultaneously present, thus rendering it available for our scrutiny.

Spontaneous perceptual judgment is "the first judgment of a person as to what is before his senses" (CP 5.115 1903) and, as Misak points out, it is also the first component of perceptual experience that can be meaningfully regarded as being true or false $(1991,76)$. However, if the discussion above is on the right track, then we are stuck with a disturbing implication that these first premises of all our knowledge misrepresent their epistemological role: for the judgment claims to be based on the perceptual image which we retain along with it; whereas in reality it appears to be either caused by the image in which the perceptual process terminates or be caused by that very perceptual process correlatively with the image to which it conceptually attaches itself. To try and address this problem we need to look closer at the anatomy of the perceptual process.

One obvious path in this venture is blocked right away by Peirce's insistence that there are no first impressions of sense, because no matter what stage of perceptual awareness we designate as initial, we can think of a stage immediately preceding, and then one before that, setting up an infinite regress all the way back to the vanishing point of consciousness (W 2.211). Hence, we cannot start with some data (the givens) of sense and ask whether our terminal image and judgment constitute, respectively, a proper synthesis and analysis thereof. The situation gets worse, because we can't even get hold of the "fleeting percepts," which still could rightly be called the evidence of the senses, for instead we have to settle for a "stenographic report of that evidence [contained in our spontaneous judgments], possibly erroneous” (CP 2.141 1902). Redeeming ourselves from ignorance and skepticism, at this point, requires introducing a hypothesis about the structure of the subconscious processes driving perception from the incipient awareness of an external impingement to the first formulated perceptual judgment. The hope is that whatever we can make out as a plausible conjecture could help us clear up the paradoxes generated so far and explain why our intrinsic trust in perceptual experience is conceptually justified.

Peirce's guess is that we should regard perceptual judgment as a result of an abductive inference, which itself comes at the end of an "infinite series of abductive inferences" which are performed subconsciously in one continuous act of perception (CP 5.181 1903). The reasons Peirce gives for thinking that perception involves abduction are mostly logical. Thus, Peirce maintains, like a good empiricist, that nothing can be in our cognition that does not first arise in some way from perceptual judgment (ibid.) But since our ideas contain a general element, this element must also be present in perceptual judgment. That perceptual judgments contain such an element can be seen from the fact that even common observation suggests that perception is essentially interpretive (CP 5.184 1903). For example, in the case of ambiguous geometrical figures (e.g. the infamous duck-rabbit case) we can see the image under completely different general aspects. Yet, as long as we focus on one of them "a certain theory of 
interpretation of the figure has all the appearance of being given in perception" and being beyond criticism, just like in any ordinary perception, but the impression of immediacy wears off as we keep switching back and forth between the two aspects (CP 5.183 1903). Examples like this suggest that perception involves an act of subsuming something under a general aspect or category; and the operation of interpreting $\mathrm{x}$ as a case of $\mathrm{y}$ is precisely what we mean by abductive inference. That we are not explicitly conscious of any inferring, in turn, is explained by the nature of abduction which is an "act of insight" that comes to us "like a flash" (CP 5.181 1903).

Abductive theory of perception explains away the apparent paradox we encountered earlier: perceptual judgment which presents itself as being based on inference is in fact based on inference, albeit of a special sort. Thus, a terminal abductive operation simultaneously invokes the judgment as the best explanation for the percept and completes the visual perception by assimilating it to an image that exemplifies (to some degree) what is typically meant by such a judgment. The account as offered leaves a lot of fundamental questions unanswered; nor does it supply a more specific description of the role which the intermediate abductive stages play in the continuous process of perception. A plausible way to advance, on the latter score, may take as a model the case where the normal operation of perception is arrested at an early stage, as in cases of surprising or unexpected perceptions that force us to stumble in the early stages of interpretation.

The original sense of resistance, of otherness, or of shock - which, on Peirce's view, characterizes every perception in some slight degree (CP 1.332 1905 ) - is greatly amplified in such cases. What we feel is resistance, indicative of a potential failure of our expectations and frustration of our beliefs but, as Misak correctly points out, the sense of resistance by itself doesn't give us a clear idea of what it is that we must believe or think at that moment $(1991,83)$. Whatever is impinging upon us is as yet outside of reasoning consciousness, and is therefore completely devoid of any determination; it is, as it were, a mere germ of its future conceptualization. If it were determined in some respect, we could render our relationship to it progressively more determinate, by trying out different predications and referring them to the object as initially (perhaps indistinctly) conceived. To decide whether the person in front of us is male we need to already be thinking of a person, to decide whether there is a person in front of us we need to be already thinking of an upright figure right ahead, etc. (comp. W 2.224). Without some initial determination, the object in front of us is almost literally unthinkable, and as Murphey pointed out, the only way to initially designate an object is through the application of a concept $(1961,137)$.

To engage an experience in the first place, we need to issue it some provisional papers of admission, assigning it a conceptual role based on essentially a hunch, so that, in this provisionally assigned capacity, it can be examined further. Our initial identification of an experience, then, takes the form of an abductive hypothesis. We may think about it, like Buchler did (1961, 39), as an 
act of theoretical projection based on a partial match between the experience and the properties associated with a certain conceptual term at our disposal; but that would leave us once again with the problem of matching logical predicates to un-conceptualized experience. It is better to say that what brings the particular term to mind, ordinarily, is our habit of thinking in those kinds of terms under the circumstances like those in question; and the features that stand out as we hazard a guess about the nature of the object in front of us are usually the same ones that activated that particular habit of recognition.

Once the provisional identification is made, we can set about refining it (if we please) by treating it as an explicit hypothesis: by transitioning from, say, "this is a mole" to "is this really a mole?" and looking around for things that may help us answer this question with more confidence. Our repertoire, here, is largely limited to the strategies which Peirce specifies as appropriate for criticizing the uncriticizable percepts and perceptual judgments: repeated exposure or re-enactment, with more attention paid to the factors that may help us resolve our doubt (CP 2.1411902 and CP 5.115 1903). The important point is that for these subsequent procedures to have any validity one would need to assume - as in fact we do - that our initial hunch is not so misleading or so far off the mark that the subsequent examination is impotent to correct it. Reasonable correctness of the initial identification is required in order for the subsequent thought or experimental manipulation to count as referring to the same experience. But as long as that is secured, we can think of the (conscious) refinement of an unfamiliar perceptual experience to the point of positive identification in terms of a chained series of "hypothetical projection - testing through additional observation" cycles: a familiar picture for the sciences that rely on special observations. Imagining that an abductive process of this sort takes place subconsciously in ordinary perception would be consistent with the general outline of Peirce's account, and makes for an empirically testable hypothesis since additional observations of the sort it suggests could, in principle, be externally tracked by eye-movements, etc. If this theory sounds plausible, it should also be kept in mind that it isn't that different from the picture with which we concluded our discussion of Wright. With abduction and subconscious processing having become increasingly familiar in contemporary philosophical discussion, there is really nothing in our account so far that a sufficiently openminded empiricist could not accept on principle. The question is whether the empiricist's fundamental assumptions entitle him to accept it.

\section{4.}

The shock of the unexpected, the initial conjecture, and the possibility of subsequent revision can all be nicely interpreted in terms of the empiricist heuristic of a conceptual framework. The primary mode of conceptual relationship featured by such an account would be coherence: to be interpreted an experience must fit in with the prior beliefs. The trustworthiness of a new 
perceptual belief would then be secured by its ability to cohere with the beliefs resulting from our previous experiences. Taking this path, however, seems to render the complicated story about the genesis of perception unnecessary: since the epistemic value of the perceptual experience is determined solely by the fit between its ultimate upshot and the network of prior beliefs, we could rest content (on the side of philosophy) with saying that the perceptual belief is caused somehow - leaving the actual "how" for the psychologists to deal with. This strategy saves us from meddling in the subconscious; yet it comes with its own drawbacks.

First of all, a perceptual belief as it emerges into consciousness already stands in some determinate relationships to other beliefs; secondly, this fact itself seems to be conveniently explained by taking perception to be interpretive, i.e. involving a kind of reasoning process; thirdly, the stages of this process as delineated by Peirce approximate our phenomenological intuitions about perceptual experience; finally, if experiential reports are to serve as a rational (albeit fallible) foundation of knowledge they cannot draw all of their cognitive force from their relationship to other sentences we hold true.

An empiricist is less concerned with the role that perception plays in our mental life and more with the effect it may have on our system of beliefs. The price of this separation is the lingering skepticism - a distinctive incarnate form of empiricist bad faith. It inevitably compels us to take seriously the distinction, featured in Rosenthal's empiricist interpretation of Peirce, between the "metaphysically real" and "the real world of facts" contained in our mind (2004, 205). I think that Rosenthal is wrong to attribute this view to Peirce, and that a pragmatist realist should refuse to credit the intelligibility of such distinctions. The difficulties that empiricist is struggling with are a product of a misconceived dualism between the causal and the rational: a gap which, it appears, can only be bridged by some kind of instrumentalist argument: e.g. it pays to be rational because it makes us successful in causal terms. But then again, for a hundred million years it paid to think like a dinosaur.

Empiricist's problem, as suggested earlier, stems, in part, from the heuristic which prompts us to picture thought as a web of belief, or a static matrix: inert, abstract, always co-present in its entirety. To be intelligible is to be mapped onto the matrix. But then perception must possess its own distinct form of intelligibility: for perception rarely fails altogether - it remains largely unfazed through the most elaborate sequences of montage and special effects; meanwhile, a failure to reconcile what we see with our prior beliefs seems like a relatively routine occurrence. Moreover, it is difficult to imagine an interaction between the system of beliefs thus conceived and the earlier stages of perception. Insofar as the emerging perception is not yet fully conscious, and most certainly not propositional, how can it conflict with a propositional system of beliefs, and how (without itself being determinate or articulate) can it frustrate a conceptually articulate expectation (of which we are seldom aware)? It is equally difficult to convince oneself that the passing theories we abductive- 
ly form on the fly to make sense of perceptual input involve a necessary reference to anything like a structured system of belief where revision can strike anywhere. Finally, the empiricist model is incapable of shedding much light on the problem of the situatedness of perception wherein its immediate intelligibility, as well as interpretation, are often thoroughly conditioned by the context in which it occurs.

A more promising line of thought would advise us that perceptual intelligibility depends on the continuity of mental processes and not merely on matching a perception to a concept. On this view, our ordinary commerce with the world is conducted not so much through the mediation of linguistically articulated beliefs but through acquired interactive habits, the deployment of which is partially conditioned by the state of one's mind at the instant of interaction. Naturally occurring perception is not an isolated instance - although we may try to isolate it in the course of an experiment - but a development within the course of experience itself. Explicit theorizing and recourse to concepts, then, is only required to bridge the unexpected discontinuities in habitual perceptual functioning.

Peirce explains that what we experience as an event in perception is a change which checks "the inertia of the mind" (CP 1.334 1905). Now, every state of the mind is characterized by the peculiar "quality of immediate consciousness" (CP 1.307 1905), an "emotion of the tout ensemble" (CP 1.311 1905), resulting from the simultaneous activity of all the processes that constitute our mental life at that instant and associated with a "readiness to respond to more than can be specified" (Rosenthal 1984, 442). This attunement or readiness to track certain kinds of input is not a conscious affair. As Peirce remarks, we are often adept at perceiving something which baffles our understanding (as when we wake up at the right hour without setting an alarm); and we are equally adept at tuning out some stimuli of an intensity that should have unconditionally commanded our attention (CP 5.185 1903). Our conscious activity can certainly modulate this "attunement," yet it is by no means under our full control.

Perception, in turn, is not an item or an instantaneous occurrence, it is a process which requires time to establish itself in consciousness. In a sense, it has to graft itself onto some pre-existing strand of cognitive activity so as to eventually grow to "its prominence in consciousness" with the ultimate perceptual awareness emerging as a "consummation" of this "growing process" (W 2.224). What we regard as an image immediately thrust upon us, then, is not the starting point of the perceptual process but merely a convenient (and psychologically significant) cross-section of it at some distance from the inception. Its growth, moreover, is not a growth in a vacuum, for the growing perceptual awareness does not put an end to the multiple, often quite unrelated, strands of thought that are running parallel to it. Every event, including perceptual events, leaves a lingering trail in thought, and, occasionally, the running strands may be joined therein as premises in a conclusion (CP 7.353 1873). 
The significance of this description lies in suggesting an important corrective to our notion of what it means for experience to be necessarily interpreted in terms of prior beliefs. The empiricist take on this suggests approaching an isolated individual incident in our experience with an interpretive table comprised of all the (internally coherent) beliefs we have managed to amass thus far. Meanwhile, Peirce's approach appears to imply that the experience is necessarily caught up by the stream of thought, which contains "a hundred things" (CP 5.284) beside its principal concerns at the moment, a stream filled with echoes, affinities, dispositions, and anticipations incapable of being articulated in propositional form. On this view, we do not pull out the periodic table of the totality of our beliefs unless the spontaneous functioning of our perceptual faculties leaves us with a sense of a downright paradox - to be addressed by an explicit theoretical construction. Our thoughts and impressions are woven together like overlapping and intertwined strands of a rope; although, for special epistemic purposes, we may reconstruct their relationship in terms of a logical matrix.

Compared to the canonical "facts" of the traditional empiricism, the pragmatist version of a perceptual belief is significantly softened. To begin with, spontaneous operation of perception never strives for a fully determinate image. An image must be determinate enough in certain respects to pass muster on a given occasion. Besides, complete determination is simply impossible for logical reasons (W 2:233). Insofar as additional determination is always possible, a perceptual belief always remains, in principle, fallible and subject to revision. Secondly, a pragmatist can never have complete confidence that his percepts are of the real world. However, she has at her disposal a system of checks that may help increase her confidence beyond the threshold of reasonable doubt, including experimental verification (CP 2.142 1902) involving an arsenal of sophisticated concepts and techniques. Yet, the logical legitimacy of such additional determinations is premised on something that appears to be an article of faith: namely, the belief that our recollections and experimental re-enactments of the original experience can serve as generic substitutes for it in the business of ascertaining its proper nature. As mentioned before, in order for such a belief to be warranted we must assume that our initial and thoroughly spontaneous identification of the content of the experience, the hunch with which the process of abductive assimilation begins below the threshold of consciousness, is accurate enough, on the majority of occasions, to serve as a suitable foundation for our consequent deliberate reconstructions of what actually took place.

What entitles the pragmatist to make this assumption? Is it anything more than a reasonable bet? Constraints of space preclude even a preliminary consideration of this issue. However, if the analysis offered above is on the right track then the problem of the intrinsic intelligibility of experience is the crucial pivot on which the distinction between pragmatism and empiricism turns. An empiricist puts perceptual experience in the service of theoretical construction, the results of which are intended to render experience in general (more) 
intelligible. A pragmatist, on the other hand, regards the perceptual experience itself as the ultimate source of all forms of intelligibility (cf. CP 5.186 1903). Hence, in the case of a recalcitrant experience, the empiricist focus is on the theoretical claims threatened by the experience, while a pragmatist focuses on the intrinsic intelligibility of the perceptual experience itself. The pragmatist position is characterized by an intrinsic openness to the conceptual suggestiveness of perceptual experience. This is an openness which, if vindicated, obviates the putative incommensurability between our experience and the concepts we use to describe it.

\section{NOTES}

1. All references to Peirce are to the collected papers edition (CP), given by volume and section, or to the chronological edition (W), given by volume and page number.

2. Peirce preferred to call Wright his "boxing master." The two were once very close intellectually. Peirce reports having "long and almost daily discussions" with Wright (CP 1.4 1897) for a period of two years. As Menand, explains, this is not particularly surprising since Wright was about the only person in Cambridge at the time who "was up to Peirce's speed in mathematics and logic" (2001, 221), and with whom Peirce could enjoy prolonged and "perfectly dispassionate" disputations about subjects like Mill's philosophy.

3. Quine is yet another empiricist who was prominently on my mind, and some references to his work occur throughout the text. Aside from historical considerations, my decision not to feature him as an explicit point of comparison was largely dictated by the rhetorical structure of the essay, which urges us to go beyond empiricism towards pragmatism, and not to retract from Quine's "radical” position to something that preceded it.

4. The relationship to positivism was explicitly recognized by Peirce who occasionally referred to his own view as "prope-positivism" (CP 5.423 1905)

5. Madden is by far the most authoritative interpreter of Wright's work. His treatment of the issue appears in the context of a broader argument against the attempts to frame Wright as a proto-pragmatist (Madden 2000, xix). Wright is not a proto-pragmatist, but this does not automatically consign him to a traditionally empiricist view of the "given."

6. References to Mill's Logic are given by book, chapter, paragraph. Information on the edition used is given in the references section.

7. Although he did believe that practical inventions which result from scientific discoveries serve as proof of the validity of scientific reasoning.

8. Coincidentally, these statements could be used, without major modifications, to express Peirce's view of the matter

9. For discussion see Hausman 1990 and Short 2000.

10. It seems to me that my expression "framed percept" is roughly equivalent to what Peirce means by "percipuum" - i.e. "the percept as it is immediately interpreted in the perceptual judgment" (CP 7.642 1903). I stick to my usage hoping to avoid terminological complications and controversy. 


\section{REFERENCES}

Buchler, Justus. 1966. Charles Peirce’s Empiricism. New York: Octagon Books.

Guiffrida, Robert. 1988. "The Philosophical Thought of Chauncey Wright: Edward Madden's Contribution to Wright Scholarship,” Transactions of the C.S. Peirce Society 24: 37-43.

Hausman, Carl. 1990. "In and Out of Peirce's Percepts," Transactions of the C.S. Peirce Society 26: 272-308.

Kuklick, Bruce. 2006. "Modern Anglophone Philosophy: Between the Seminar Room and the Cold War,” Modern Intellectual History 3: 547-557.

Madden, Edward. 1953. "Pragmatism, Positivism, and Chauncey Wright," Philosophy and Phenomenological Research 14: 62-71.

Madden, Edward. 1958. "Introduction," in The Philosophical Writings of Chauncey Wright: Representative Selections, ed. Edward Madden (New York: Liberal Arts Press), pp. vii-xx.

Madden, Edward. 1963. Chauncey Wright and the Foundations of Pragmatism. Seattle: University of Washington Press.

Madden, Edward. 1972. "Chauncey Wright and the Concept of the Given,” Transactions of the Charles S. Peirce Society 8: 48-52.

Madden, Edward. 2000. "Introduction” in The Evolutionary Philosophy of Chauncey Wright. Volume 3: Influence and Legacy, ed. Frank Ryan and Edward Madden (Bristol: Thoemmes Press), pp. vii-xxv.

Menand, Louis. 2001. The Metaphysical Club: A Story of Ideas In America. New York: Farrar, Straus, and Giroux.

Mill, John Stuart. 1961. A System of Logic Ratiocinative and Inductive. London: Longmans.

Misak, Cheryl. 1991. Truth and the End of Inquiry: A Peircean Account of Truth. Oxford: Clarendon Press.

Murphey, Murray. 1961. The Development of Peirce's Philosophy. Cambridge, Mass.: Harvard University Press.

Peirce, Charles Sanders. 1932-1958. Collected Papers of Charles Sanders Peirce, 8 vols., ed. Charles Hartshorne, Paul Weiss, and Arthur Burks. Cambridge, Mass.: Harvard University Press.

Peirce, Charles Sanders. 1984-. Writing of Charles S. Peirce: A Chronological Edition, 6 vols. to date. Bloomington: Indiana University Press. 
Putnam, Hilary. 2002. The Collapse of the Fact/Value Dichotomy and Other Essays. Cambridge, Mass.: Harvard University Press.

Rosenthal, Sandra. 1984. “Temporality, Perceptual Experience and Peirce’s "Proofs” of Realism,” Transactions of the C.S. Peirce Society 20: 435-452.

Rosenthal, Sandra. 2004. "Peirce's Pragmatic Account of Perception: Issues and Implications," in The Cambridge Companion to Peirce, ed. Cheryl Misak (Cambridge, UK: Cambridge University Press), pp. 193-213.

Sellars, Wilfrid. 1997. Empiricism and the Philosophy of Mind. Cambridge, Mass.: Harvard University Press.

Short, Thomas. 2000. "Was Peirce a Weak Foundationalist?” Transactions of the C.S. Peirce Society 36: 503-528.

Wright, Chauncey. 1958. The Philosophical Writings of Chauncey Wright: Representative Selections, ed. Edward Madden. New York: Liberal Arts Press.

Wright, Chauncey. 2000. The Evolutionary Philosophy of Chauncey Wright. Volume 1: Philosophical Discussions, ed. Frank Ryan. Bristol, UK: Thoemmes Press.

Wright, Chauncey. 2000a. The Evolutionary Philosophy of Chauncey Wright. Volume 2: Letters of Chauncey Wright, ed. Frank Ryan. Bristol, UK: Thoemmes Press.

Serge Grigoriev

Department of Philosophy and Religion

Ithaca College

953 Danby Road

Ithaca, New York 14850

United States 